\title{
OS AVANÇOS DA HISTÓRIA ANTIGA NO BRASIL: ALGUMAS PONDERAÇÕES
}

\author{
Margarida Maria de Carvalho ${ }^{1}$ \\ Pedro Paulo A. Funari ${ }^{2}$
}

As pesquisas de História Antiga, no Brasil, remontam aos inícios da disciplina, no âmbito universitário. Eurípides Simões de Paula, um dos primeiros historiadores universitários - grande propugnador da disciplina histórica, na recém-criada Universidade de São Paulo -, fundou a cadeira de História Antiga, tendo sido o primeiro catedrático. Sua tese de doutoramento já se destacava pela ambição de inserir-se no âmbito internacional e, ao mesmo tempo, por estudar a periferia, algo particularmente inovador ${ }^{3}$.

Contudo, por muitas décadas, a História Antiga manteve-se como especialidade pouco difundida nos cursos de História, que se multiplicaram exponencialmente a partir da década de 1940. Seria apenas nas últimas décadas do século XX que a História Antiga começaria a expandir-se, primeiro nas universidades mais antigas e centrais, para, aos poucos, atingir as instituições mais novas e mais distantes. Tal fato será verificado quando apresentarmos os autores dos artigos e resenhas desse dossiê.

Dessa forma, revela-se na década de 1970, quanto à expansão da disciplina no território nacional, uma produção marcada pela repressão da ditadura militar. A História Antiga será vista, no setor universitário, como controle ideológico e, assim, será identificada com a chamada Direita política do país. Nos currículos de História das grandes universidades brasileiras haverá o predomínio da História Antiga adotada de maneira factual, bastante positivista, fator esse que irá ao encontro dos objetivos da censura.

Os espaços das reflexões sociopolíticas, tão características e inerentes aos cursos de História, serão preenchidos por uma Antiguidade maniqueísta, olhada como algo curioso e não como um convite à análise dos processos históricos. Essa mácula, quase indelével, ficará durante muito tempo nos registros dos historiadores brasileiros 
especialistas em História do Brasil, da América, História Moderna e Contemporânea, os quais não medirão esforços para combater tais estudos sobre História Antiga, apesar do empenho, após a abertura política ocorrida na década de 1980, da maioria dos antiquistas brasileiros em desconfigurar essa imagem distorcida ao acompanhar o novo resplendor da historiografia marxista.

A partir de então, a produção de pesquisadores em Antiguidade não cessará em acompanhar os avanços da historiografia. Detentores do conhecimento das denominadas línguas mortas: aramaico, sânscrito, grego e latim e, fundamentalmente, de línguas estrangeiras como espanhol, inglês, francês, italiano e alemão ${ }^{4}$, os estudiosos na área da Antiguidade terão acesso a tais avanços, como, por exemplo, à imprescindível contribuição analítica do historiador americano Moses Finley, atuante na Grã-Bretanha, que revolucionou a estrutura da análise da História Antiga ao criticar o modelo marxista com suas sínteses totalizadoras transplantadas pelas revoluções, elucidando a eficácia do conceito de ordem e status de inspiração weberiana em detrimento do emprego do conceito de classe social no que se refere à interpretação do que seriam os grupos sociais na antiguidade clássica.

Os historiadores antiquistas nacionais acompanharão, muito atentos, os desdobramentos dessa interpretação, concordando ou não com essa premissa, mas não deixando de respeitar a obra de Finley, cujo aparato bibliográfico nos inspira até os dias atuais. As críticas às abordagens normativas inspiradas em Weber, a partir da década de 1990, só podem ser compreendidas pela absorção das propostas da Escola de Cambridge no país ${ }^{5}$.

Os conflitos sociais ocorridos na Antiguidade serão analisados sob prismas mais arrojados, e com o conhecimento da Nouvelle Histoire novos temas serão pesquisados em nossa área. A partir de meados da década de 1990, com o advento da História Cultural expandindo-se em nível nacional, houve uma multiplicação de Dissertações e Teses influenciadas pelo conceito de representação, o qual, mais tarde, no clarão do século XXI, será articulado à análise do discurso.

O respeito pelo trato documental, sua datação e autoria, críticas internas e externas dos discursos, sua linguagem metafórica, enfim, a desconstrução do discurso serão albergados à luz das tropas de reconhecimento da pós-modernidade. Sempre aliados ao conhecimento documental e historiográfico, os investigadores antiquistas escolherão seus métodos, técnicas e teorias de abordagem, associando tais interpretações à análise iconográfica e à cultura material. 
Essa expansão no Brasil deu-se, portanto, em um contexto de renovação da historiografia em geral, e, conseqüentemente, sobre a Antigüidade, em particular. A Historiografia passou a interagir cada vez mais intensamente com as outras Ciências Humanas e Sociais, em busca de interpretações que superassem as aporias teóricas e práticas do estudo das sociedades no presente e no passado. A multiplicação dos movimentos sociais e a explosão de conflitos e de identidades, com mais força desde a década de 1960, levaria a crítica aos modelos normativos ${ }^{6}$. A historiografia sobre o mundo antigo não deixaria de inserir-se nessa renovação, com a multiplicação de estudos e abordagens contextuais e antinormativas ${ }^{7}$. As leituras modernas da Antigüidade foram incorporadas à lide quotidiana da disciplina ${ }^{8}$. A pesquisa de História Antiga no Brasil insere-se neste contexto. Cada vez mais atenta à sua inserção nas discussões internacionais, não hesita, também, em mostrar como as especificidades brasileiras podem ser usadas, de maneira produtiva e fertilizadora, para contribuir com os debates nos ambientes hegemônicos. Deve-se também destacar a interação da História Antiga com o estudo da História de outros períodos e épocas ${ }^{9}$. Foi com o sentido de esclarecer tais considerações que organizamos esse dossiê.

Este volume, entretanto, não pretendeu abranger a imensa variedade da produção nacional: isso superaria, em muito, o espaço disponível. Preferimos apresentar uma amostra dessa mesma variedade, sabedores de que outras tantas iniciativas têm contribuído e continuarão a contribuir para a complexa tarefa de difundir a História Antiga produzida no Brasil. Assim, nesse empreendimento, destacam-se somente nove autores de artigos e três autores de resenhas de livros recentemente publicados em nosso país.

Abrindo o leque de discursos investigativos aqui apresentado, em sua totalidade por professores de História Antiga, temos o trabalho de Ana Teresa Marques Gonçalves - do Departamento de História da Universidade Federal de Goiás (UFG) - intitulado Septímio Severo e a Consecratio de Pertinax: Rituais de Morte e Poder, no qual a autora analisa a cerimônia de deificação do Imperador Pertinax ocorrida após a sua morte (século III d.C.). O texto de Andréa L.D.C. Rossi - do Departamento de História da Unesp/Assis e partícipe do Núcleo de Estudos Antigos e Medievais das Unesp Assis/Franca - leva-nos ao conhecimento de Mitologia: Abordagem Metodológica para o Historiador da Antiguidade Clássica, onde a historiadora propõe uma aplicação da análise da semiótica na interpretação da obra de Dion Chrisóstomo, mais conhecido como Dion de Prusa, filósofo bitiniano que viveu entre 40 e 115 d.C. Com Fábio 
Faversani - do Departamento de História da Universidade Federal de Ouro Preto (UFOP) -, percorremos o caminho para a compreensão de O Estado Imperial e os Pequenos Impérios, onde o autor focaliza o tema na obra de Sêneca, filósofo estóico do período neroniano. Ao nos debruçarmos sobre o texto de Fábio Vergara Cerqueira - do Departamento de História da Universidade Federal de Pelotas (UFPEL) -, passamos a conhecer melhor A Imagem Pública do Músico e da Música na Antiguidade Clássica: Desprezo ou Admiração?, no qual o autor analisa as representações que definem o músico no imaginário social das sociedades grega e romana antigas. Já Gilvan Ventura da Silva - do Departamento de História da Universidade Federal do Espírito Santo (UFES), uma das poucas referências do Brasil em estudos específicos sobre os séculos IV e V d.C., disserta a respeito de Ascetismo, Gênero e Poder no Baixo Império Romano: Paládio de Helenópolis e o Status das devotas cristãs. Através da obra História Lausíaca de Paládio, o investigador interpreta o papel das ascetas no movimento monástico dominado pelos homens. O historiador Glaydson José da Silva pesquisador do Núcleo de Estudos Estratégicos da Unicamp - apresenta um trabalho que trata da interface História Contemporânea/História Antiga quando, em $O$ Mundo Antigo visto por Lentes Contemporâneas: as extremas direitas na França nas décadas de 80 e 90, ou da instrumentalidade da antiguidade, o autor interpreta os usos do passado pelas extremas direitas francesas como formas de se compreender a contemporaneidade; linha de pesquisa que vem tomando vulto desde meados da década de 1990 e se fortalecendo cada vez mais atualmente.

Dando seqüência ao dossiê, temos o artigo de Ivan Esperança Rocha - do Departamento de História da Unesp/Assis e Coordenador do Núcleo de Estudos Antigos e Medievais das Unesp Assis/Franca -, cujo título, Imagem do Judaísmo: Aspecto do Aniconismo Identitário, refuta que as formas visuais vêm ganhando um espaço significativo nos estudos da Antiguidade, pois a historiografia tem considerado sua capacidade de representar os imaginários sociais e de evidenciar as mentalidades coletivas. Com Norberto Luiz Guarinello - do Departamento de História da USP adquirimos conhecimento com Violência como Espetáculo: o pão, o sangue e o circo. Nesse trabalho, de uma forma bastante dinâmica, Guarinello constrói um diálogo constante entre a violência da contemporaneidade e a noção da mesma na Antiguidade. Finalmente, o último artigo, de Renata Senna Garrafoni - do Departamento de História da Universidade Federal do Paraná (UFPR) -, Os Bandidos entre os romanos: Leituras Eruditas e Percepções Populares, esclarece como a elite romana visualizava os 
bandidos antigos na literatura satírica e que, por meio de estudos epigrafemos, pode-se analisar a imagem do roubo na cultura popular.

Na seção final do volume, encontram-se as resenhas de livros de autores do país, publicados nos últimos dois anos. Cláudio Umpierre Carlan ${ }^{10}$ - Doutorando do Programa de Pós-Graduação em História da Unicamp e pesquisador do Núcleo de Estudos Estratégicos - resenha o livro da historiadora Lourdes M. G. Conde Feitosa, Amor e Sexualidade: o masculino e o feminino em grafites de Pompéia. Fábio Duarte Joly - professor do Departamento de História da Universidade Federal do Recôncavo Baiano (UFRB) - tece comentários críticos sobre o livro da autora Marilena Vizentin, Imagens do Poder em Sêneca: estudos sobre o De Clementia, e Maria Aparecida de Oliveira Silva ${ }^{11}$ - Doutoranda do Programa de Pós-Graduação em História Social do Departamento de História da USP - redigiu a súmula crítica do livro de Renata Senna Garrafoni, Gladiadores na Roma Antiga: dos Combates às Paixões Cotidianas. Todas essas resenhas são um convite instigante aos leitores do mundo acadêmico ou para todos aqueles que gostam e valorizam a História Antiga.

Enfim, a riqueza dos artigos e das obras resenhadas confirmam nossas alusões anteriormente expostas acerca dos avanços historiográficos realizados pela produção nacional, demonstrando que a História Antiga está mais viva do que nunca. Nesse sentido, a residual obtusidade daqueles que insistem em não valorizar as pesquisas dessa área, certamente, será questionada, uma vez mais, com o trabalho profícuo aqui desenvolvido.

\section{Agradecimentos}

Agradecemos aos editores da História/Unesp, Prof. Dr. Carlos Alberto Sampaio Barbosa e Profa. Dra. Tânia da Costa Garcia, e à sua comissão editorial pelo espaço concedido à publicação desse dossiê. A todos os autores do volume, assim como mencionamos o apoio institucional do CNPq, do Núcleo de Estudos Estratégicos (NEE/Unicamp), Departamento de História da Unicamp e Departamento de História da Unesp/Franca, assim como ao Núcleo de Estudos Antigos e Medievais das Unesp Assis/Franca. À Helena Amália Papa - mestranda em História Antiga do Programa de Pós-graduação em História da Unesp/Franca, pelo apoio à organização desse dossiê. A 
responsabilidade das idéias aqui apresentadas é da ordem exclusiva dos autores desta apresentação.

\footnotetext{
${ }^{1}$ Departamento de História da Unesp/Franca, Pós-Doutoranda em História Antiga , com apoio do CNPq, - Bolsa de Pós-Doutorado Júnior - no Departamento de História da Unicamp e do Núcleo de Estudos Estratégicos da mesma Instituição, sob a supervisão do Prof. Dr. Pedro Paulo A. Funari. Partícipe do Núcleo de Estudos Antigos e Medievais das Unesp Assis/Franca.

2 Departamento de Hstória da Unicamp, Coordenador-Associado do Núcleo de Estudos Estratégicos (NEE/Unicamp).

${ }^{3}$ Marrocos e suas relações com a Ibéria na Antiguidade, 1946.

${ }^{4}$ Exige-se, de qualquer historiador que pretenda ser um antiquista, o conhecimento de, pelo menos, uma língua morta e duas línguas estrangeiras.

${ }^{5}$ Cf. FUNARI, P. P. A. Júlio César, poder, instituições e jurisdições na construção biográfica de Plutarco. In: GUIMARÃES, Marcella Lopes; FRIGHETTO, Renan (Org.). Instituições, poderes e jurisdições. Curitiba: Juruá, 2007. , p.175-180.

${ }^{6}$ Cf. MUNSLOW, Alun. Deconstructing history. Londres: Routledge, 1997.

${ }^{7}$ Cf. FUNARI, Pedro Paulo A. A renovação no ensino de História Antiga. In: KARNAL, Leandro (Org.). História na Sala de Aula. São Paulo: Contexto, 2003. p.95-108, com referências.

${ }^{8}$ E.g. CARVALHO, Margarida Maria de. Interpretações Críticas sobre algumas Biografias do Imperador Juliano dos séculos XIX e XX. In: ANDRADE FILHO, Ruy de Oliveira (Org.). Relações de poder, cultura e educação na Antiguidade e Idade Média. 1. ed. São Paulo: Solis, 2005. p.217-226.

${ }^{9}$ E.g. CARVALHO, Margarida Maria de; LOPEZ, M. A. S.; FRANÇA, S. S. L. (Orgs.). As cidades no tempo. 1. ed. São Paulo: Olho d'Água, 2005. v. 1.323 p.

${ }^{10}$ Doutorando do Prof. Dr. Pedro Paulo Funari.

${ }^{11}$ Doutoranda do Prof. Dr. Norberto Luiz Guarinello.
} 